\title{
Research Paper: The Effect of Selected Yoga Exercises on Thoracic Spine Alignment and Respiratory Capacity in Children With Asthma
}

\author{
Mahboobeh Ahmadi Rekabdar ${ }^{1}$ (D), Parisa Sedaghati ${ }^{*}$ (D) \\ 1. Department of Sport Injuries and Corrective Exercises, Faculty of Physical Education and Sport Sciences, University of Guilan, Rasht, Iran.
}



ditation Ahmadi Rekabdar M, Sedaghati P. The Effect of Selected Yoga Exercises on Thoracic Spine Alignment and Respiratory Capacity in Children With Asthma. Physical Treatments. 2021; 11(2):85-92. http://dx.doi.org/10.32598/ptj.11.2.406.2

http://dx.doi.org/10.32598/ptj.11.2.406.2

\section{(1) (3)}

Article info:

Received: 29 Sep 2020

Accepted: 29 Oct 2020

Available Online: 01 Apr 2021

Keywords:

Asthma, Spirometry, Kyphosis, Yoga;, Thoracic spine curvature

\begin{abstract}
A B S T RA C T
Purpose: People with asthma often have sedentary lifestyles and are less physically, mentally, and cardio-respiratory prepared than their peers. Therefore, the present study aimed to investigate the effect of selected Yoga exercises on thoracic spine alignment and respiratory capacity indices in children with asthma.

Methods: The present research is a quasi-experimental study with a pretest-posttest design. For this purpose, 30 children with mild asthma were included in the study purposefully and voluntarily. The subjects were randomly divided into a control group (15 people with Mean $\pm \mathrm{SD}$ age: $11.40 \pm 2.13$ years) and an experimental group (15 people with Mean \pm SD age: $10.60 \pm 1.76$ years). Written informed consent was obtained from the parents of the children. Flexible ruler and spirometry were used to evaluate the curvature of the thoracic spine and respiratory capacity, respectively. To analyze the results of this study, we used a dependent t-test and analysis of covariance at a significance level of $\mathrm{P}<0.05$.
\end{abstract}

Results: The results showed a significant difference between the two groups in terms of thoracic spine curvature $(\mathrm{P}=0.001)$ and increased respiratory capacity $(\mathrm{P}=0.001)$.

Conclusion: Breathing exercises and asanas of Yoga positively influence the extensor muscles of the chest and improve lung function and postural misalignment in children with asthma. Therefore, therapists, coaches, and exercise teachers are recommended to use Yoga exercises to improve the physical, postural, and respiratory indices of children with asthma.

\section{"Corresponding Author:}

Parisa Sedaghati, $P h D$.

Address: Department of Sport Injuries and Corrective Exercises, Faculty of Physical Education and Sport Sciences, University of Guilan, Rasht, Iran. Phone: +98 (13) 33690260

E-mail: sedaghati@guilan.ac.ir 


\section{Highlights}

- Yoga exercise improved the thoracic spine curvature in asthmatic patients.

- Yoga exercise increased the respiratory capacity and volume in asthmatic patients.

\section{Plain Language Summary}

Children with asthma often are less physically and mentally active than normal ones. Eventually, they develop abnormal body postures and have difficulty in breathing. In this study, we tried to answer whether Yoga practice can correct chest misalignment and respiratory problems in asthmatic children. For this purpose, 30 children with mild asthma were randomly divided into the control and experimental group. After the intervention, the findings showed that Yoga exercise corrected spinal misalignment and increased lung capacity in children with asthma.

\section{Introduction}



ver 1.5 billion people suffer from chronic respiratory diseases, with over 4 million annual death worldwide [1]. Asthma is among the most common chronic respiratory diseases and the main health concern in most societies and Iran [2]. According to the latest reports, the prevalence of asthma among adults and adolescents is $13 \%$, increasing over the last decade [2]. One of the essential and fundamental principles for preventing and controlling asthma is the standardization of services for the diagnosis, treatment, and care of the disease at different levels. This endeavor requires the development of national guidelines according to the native facilities [3]. It is well known that Yoga exercises improve the respiratory capacities of asthmatic patients $[4,5]$. Although unfamiliar in our country, Yoga has been recognized by American and European researchers for its positive effect on both the human body and soul [6]. Some studies reveal the positive and beneficial effects of Yoga [7]. Yoga exercises and pranayama control asthma signs [8]. Pranayama in Yoga includes controlled respiratory techniques, e.g. elongation, holding, and shortening of breath voluntarily by controlling respiratory muscles [7].

The corrected pattern of respiration in Yoga results in the activation of dead lung spaces, improving circulation, producing new mast cells, boosting children's immune system, and better controlling asthma signs [8]. When the Yoga exercises were used, patients experienced not only improvement in pulmonary capacity, function, and ventilation but also promotion of respiratory strength and flexibility [9]. However, asthma in children results in chest immobility, shortening of pectoral muscles, increased kyphosis, shortening of neck muscles, and round shoulders. Such changes in posture results in pain, disability, and respiratory dysfunction [10]. Some mechanisms, e.g. respiratory muscle strengthening, shortening hospitalization, decreasing bronchodilators improve respiratory function, and ventilation of spirometry parameters in asthmatic patients [11]. In this regard, Turan et al., in a controlled randomly designed study, reported the positive Yoga effect on respiratory function, disease control, and quality of life of asthma patients [12].

Brzek et al. studied the effect of physical activity on asthmatic children's posture and reported the positive effect of physical activity on the horizontal and longitudinal diameter of the chest [13]. Also, Soni et al studied the efficient use of a two-month asana Yoga on pulmonary diffusion capacity in asthma [14]. In another research on the control of asthma by Yoga, Mekonnen et al. and Sodhi et al. demonstrated its beneficial impact on life quality, lung function, and the disease attack [15, 16]. Yoga improves lung function and quality of life, and the golden rules in Yoga signify the correct body alignment, especially the spinal cord. The pranayama guidelines emphasize respiratory exercise and a higher prevalence of postural disorders in the cervicothoracic column among asthmatic children $[17,18]$. We aimed to investigate the effect of selected Yoga exercises on thoracic spine alignment and respiratory capacity indices in children with asthma.

\section{Materials and Methods}

This quasi-experimental study has a pretest-posttest design with a control group. The participants were asthmatic children referred to Hefdahe Shahrivar Hospital (Rasht City, Iran), and the research was carried out there. The research was approved by the Ethics Committee of Guilan University of Medical Sciences (Code: 
Table 1. Individual information of the subjects

\begin{tabular}{|c|c|c|c|c|}
\hline Variables & Groups & Mean $\pm S D$ & $\mathbf{t}$ & $\mathbf{P}$ \\
\hline & Control & $11.40 \pm 2.13$ & & \\
\hline \multirow[t]{3}{*}{ Age $(y)$} & & & 1.12 & 0.27 \\
\hline & Experimental & $10.60 \pm 1.76$ & & \\
\hline & Control & $1.49 \pm 0.06$ & & \\
\hline \multirow[t]{3}{*}{ Height (cm) } & & & 2.03 & 0.051 \\
\hline & Experimental & $1.43 \pm 0.09$ & & \\
\hline & Control & $43.13 \pm 11.83$ & & \\
\hline \multirow[t]{2}{*}{ Weight (kg) } & & & 1.31 & 019 \\
\hline & Experimental & $37.86 \pm 9.99$ & & \\
\hline \multirow{3}{*}{ Body mass index $\left(\mathrm{kg} / \mathrm{m}^{2}\right)$} & Control & $19.10 \pm 4.68$ & & \\
\hline & & & 0.78 & 0.44 \\
\hline & Experimental & $18.01 \pm 2.70$ & & \\
\hline \multirow{3}{*}{ Duration of asthma (y) } & Control & $3.46 \pm 1.59$ & & \\
\hline & & & 0.37 & 0.70 \\
\hline & Experimental & $3.26 \pm 1.27$ & & \\
\hline
\end{tabular}

IR.GUMS.REC.1398.538), and all steps of the study were performed according to the Helsinki Declaration. Informed consent was taken from all participants. The participants ( $\mathrm{N}=30$, aged: 8-14 years) were boys and girls with no sign of puberty which were purposefully assigned to two random groups: Yoga Exercise Group (YEG) and Control Group (COG) ( $\mathrm{n}=15$ for each group). All prescribed drugs were continued during the study.

The inclusion criteria were a history of mild asthma with verification of a medical specialist, no regular physical activity, and the agreement of children and parents. The exclusion criteria were history of severe cardiopulmonary, musculoskeletal, and infectious disease, weakness and disability in performing Yoga exercises, intermittent performing of exercises and more than two sessions absence in exercises, and the reluctance of children and parents to take part. In the pretest stage, thoracic spinal curvature and respiratory capacities were measured. Then YEG group performed selected Yoga exercises consisting of combinations of asanas and pranayama movements for eight weeks, three sessions each week, and each session 30-45 min. However, COG did not perform any activity unless their routine activities. Following the eighth session, similar to the pretest stage, all variables were measured in two groups.

To measure the thoracic curvature, we used a $40-\mathrm{cm}$ flexible ruler (Kagran, Iran) (precision of $0.1 \mathrm{~mm}$ and reliability coefficient of 97\%) [19]. The participant was in a relaxed standing position with his bare feet shoulderwidth apart. While the participant was in a standing po- sition, the researcher behind the participant marked the $\mathrm{T} 2$ and $\mathrm{T} 12$ spinous processes as the beginning and end of the spinal curvature, respectively. Then the ruler was placed along with the marked points on the body, and the spinal curvature-shaped ruler was transferred on a sheet of paper to determine the T2 and T12 points on paper. A straight line was drawn between T2 and T12 points, and the length of the line was determined as L. After that, a vertical line beginning from the deepest curvature was drawn to transect the L line, and the depth of the curvature $(\mathrm{H})$ was measured. To yield the curvature angle $(\Theta)$, the respective values were replaced in $\Theta=(4 \operatorname{Arc} \tan 2 \mathrm{~h} / 1)$ equation [20].

To measure the respiratory volumes and capacities, we used spirometry. The measured spirometry indices were Forced Expiratory Volume in one second and Forced Vital Capacity (FEV1/FVC). While sitting on a special chair and wearing a nose clamp, the test was taken by a spirometry technician as follows. After wearing a nose clamp and passing a 2-min respiratory test to allow the participant to resume his/her breathing, the participant exhaled into the spirometer following a deep inspiration. The maximum value among the three exertional trials was registered [21].

The Yoga protocol consisted of different yoga asanas: Padmasana, Yoga Mudra, Matsyasana, Kukkutasana, Uthana Padasana, Pavanmuktasana, Paschimottanasana; Dhanurasana, Supta Vajrasana, Gomukhasana, Viparita Karani, Sarvangasana, Halasan, Karnapidasana, Bhujangasana, Bakasana, Mandukasana, Parvatasana, Nauli 
Table 2. Results of Analysis of Covariance to compare variables in the posttest between groups

\begin{tabular}{|c|c|c|c|c|c|c|}
\hline Variables & Test Phase & Groups & Mean* & $\mathbf{F}$ & $\mathbf{P}$ & Eta Squared \\
\hline \multirow{3}{*}{ Curvature of the thoracic spine } & Posttest & Control & 35.35 & & & \\
\hline & & & & 10.36 & $0.003^{* *}$ & 0.27 \\
\hline & Posttest & Experimental & 34.39 & & & \\
\hline \multirow{3}{*}{ FEV1 } & Posttest & Control & 90.47 & & & \\
\hline & & & & 21.09 & $0.001^{* *}$ & 0.43 \\
\hline & Posttest & Experimental & 94.46 & & & \\
\hline \multirow{3}{*}{ FEV1/FVC } & Posttest & Control & 93.86 & & & \\
\hline & & & & 30.40 & $0.001^{* *}$ & 0.53 \\
\hline & Posttest & Experimental & 97.33 & & & \\
\hline
\end{tabular}

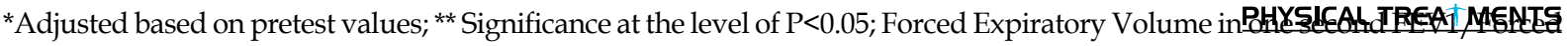
Vital Capacity(FEV1/FVC).

and Shavasana. The Pranayam protocol consisted of deep breathing, inhalation-retention-exhalation at fixed intervals, abdominal (diaphragmatic) breathing and alternate nostril breathing [22, 23], and Kapalabhati breathing [24]. Considering the overload principle of exercises, the training sessions gradually increased in frequency and training volume. All children and their parents were first educated about the training protocol for three sessions. The educational $\mathrm{CD}$ of the protocol was given to the parents, and the whole procedure at home was followed via cell phone and virtual media. After assessing the normality of data, the Shapiro-Wilk, dependent t-test, and covariance tests were used to analyze data. The significant level was considered as $\mathrm{P}<0.05$.

\section{Results}

The demographic characteristics of the participants are presented in Table 1. The analysis of covariance (ANCOVA) of the pretest (covariate) data for spinal curvature and respiratory variables (FEV1 and FEV1/FVC) in the posttest showed the difference between YEG and COG groups $(\mathrm{P}<0.05)$ (Table 2$)$.
According to Table 3, the dependent t-test revealed a significant difference in the effect of selective Yoga exercises on thoracic curvature and spirometry parameters of the participants $(\mathrm{P}<0.05)$. However, in the COG group, no significant difference was revealed for thoracic curvature and spirometry parameters between pretest/posttest scores following 8 weeks exercises.

\section{Discussion}

The objective of the present study was to explore the effect of selected yoga exercises on thoracic spine alignment and respiratory capacity indices in children with asthma. The findings revealed that 8 weeks of selected Yoga exercises significantly affected thoracic spine alignment and respiratory capacity indices in children with asthma. Our findings also revealed a positive relation between performing Yoga exercises and thoracic spine alignment and respiratory capacity indices in children with asthma. Thoracic misalignment due to overuse of main and auxiliary respiratory muscles and the pattern of oral respiration among asthmatic patients resulted in spinal structural abnormalities [25, 26]. Gonçalves et al., in a study of posture in severe asthmatic patients, revealed spinal cord structural abnormalities (head-forward

Table 3. The paired t-test results, the difference between pretest and posttest in groups

\begin{tabular}{|c|c|c|c|c|c|c|c|c|}
\hline \multirow{3}{*}{ Variables } & \multicolumn{4}{|c|}{ Experimental Group(n=15) } & \multicolumn{4}{|c|}{ Control Group ( $n=15)$} \\
\hline & \multicolumn{2}{|c|}{ Mean $\pm S D$} & \multirow{2}{*}{$\mathbf{t}$} & \multirow{2}{*}{$\mathbf{P}$} & \multicolumn{2}{|c|}{ Mean $\pm S D$} & \multirow{2}{*}{$\mathbf{t}$} & \multirow{2}{*}{$\mathbf{P}$} \\
\hline & Pretest & Posttest & & & Pretest & Posttest & & \\
\hline $\begin{array}{l}\text { Curvature of the } \\
\text { thoracic spine }\end{array}$ & $36.04 \pm 5.61$ & $34.89 \pm 4.93$ & 3.58 & $0.003^{*}$ & $34.96 \pm 4.44$ & $34.86 \pm 4.44$ & 1.48 & 0.16 \\
\hline FEV1 & $89.73 \pm 4.38$ & $94.80 \pm 2.59$ & -5.78 & $0.001^{*}$ & $88.73 \pm 5.20$ & $90.13 \pm 5.01$ & -2.62 & 0.05 \\
\hline FEV1/FVC & $92.26 \pm 3.67$ & $96.40 \pm 2.94$ & -8.49 & $0.001^{*}$ & $95.13 \pm 5.76$ & $94.80 \pm 4.03$ & 0.47 & 0.64 \\
\hline
\end{tabular}

* Significance at the level of $\mathrm{P}<0.05$ 
posture, round-shouldered, thoracic kyphosis) due to asthmatic respiration pattern [27]. Almeida et al. found a significant relationship between pulmonary function, posture, and body composition and proposed a better therapeutic approach in such patients based on postural correction and the improvement of respiratory function [28].

All findings demonstrate spinal structural in asthmatic patients. However, Dias studied head, shoulder, and spinal alignment in oral respiration compared to nasal one and found no difference because of the growth and weight abnormalities of children [29]. Although most studies used movement interventions and brace instead of Yoga in hyperkyphotic cases, similar findings were observed. The agreement between our study and the mentioned ones may be due to the nature and structure of the common bodily exercises. Corrective exercises use the stretching and strengthening techniques for shortened muscles to correct the posture, and asanas use the same stretching and strengthening exercises while emphasizing the performance of movements and pranayama affects the chest dispensability [30].

Emphasis on deep respiration is part of Yoga, and performing each movement is related to awareness, respiration, and the whole body. During stretching and respiratory Yoga exercises, the respiratory rate decreases, and lung capacity increases [7]. Similarly, Erdoğan Yüce studied the effect of pranayama respiratory techniques on asthma control, pulmonary function, and quality of life in asthma patients and reported the positive effect of the mentioned techniques following one-month exercise with no significant difference in pulmonary function [31]. Many studies reveal the benefit of combinational asanas and pranayamas on improving pulmonary capacities than the effect of different asanas or pranayama's exercise [12, 23, 32, 33]. Moreover, the observed combinational effect may be the reason for the discrepancy between Erdoğan Yüce and the present study in term of the effectiveness of Yoga on respiratory capacity, signifying the application of pranayama respiratory technique per se in Erdoğan Yüce study [31].

Another reason for the discrepancy may be because of the method of performing the movements. In Erdoğan Yüce study, following a 3-day educational session, a video on the pranayama technique was loaded in their cell phones, and the participants were required to perform the respiratory techniques for at least 20 minutes daily through viewing the educational video. However, in the present study, after a face-to-face educational session, all classes were held online under the supervision of a researcher, three sessions each week, each session took
30-45 minutes. Many studies report the positive effect of Yoga on the physical and mental status of children. On performing the Yoga, combined asanas and pranayama result in discharging the pulmonary secretions. Through respiratory techniques, Yoga depletes negative energy and stimulates respiratory ducts to make effective cough for discharging pulmonary secretions $[1,5,8,34]$.

According to previous studies, training Yoga exercises increases respiratory capacity and volume, chest flexibility, and expansion [24]. Also, there is an agreement between our study and Sedaghati's study comparing the effect of a course of corrective exercise and typing the spinal cord on kyphosis and chest anthropometric indexes among the senile hyperkyphotic women and reported a significant effect on thoracic curvature $[35,36]$. Besides improving respiratory condition, our study reveals the impact of Yoga on posture, as previously reported by Halvorson et al.. Respiratory function depends on different factors, including neural function, respiratory muscle strength, and lungs [37].

To mention the limitations, we did not apply strict supervision on performing the exercise protocol due to the COVID-19 pandemic, and only a few face-to-face sessions were held, and the remaining sessions were followed online at home. Considering the present study results, it is suggested that sports coaches use our exercise protocol in therapeutic and sports centers for mild asthma patients.

\section{Ethical Considerations}

\section{Compliance with ethical guidelines}

All ethical principles were observed in this article. The participants were thoroughly informed about the research and its implementation stages. They were also assured about the confidentiality of their information; moreover, they were allowed to leave the study whenever they wanted, and if desired, the results of the research would be available to them. After describing the test protocol to all cases before participating in the study, they all filled out an informed consent form (Ethics Code: IR.GUMS. REC.1398.538).

\section{Funding}

This article is part of an MA thesis at Sport Injuries and Corrective Exercises from a research project of the first and second author, Guilan University of Medical Sciences. 


\section{Authors' contributions}

Both authors equally contributed to preparing this article.

\section{Conflict of interest}

The authors declared no conflicts of interest.

\section{Acknowledgments}

The authors would like to thank Dr. Kourosh Fakhimi (sub-specialist in Pediatric Respiratory disease) and Hamid Zolghadr for their valuable cooperation and the kind participation of cases in this study.

\section{References}

[1] Wise J. Yoga may improve asthma symptoms, Cochrane review finds. British Medical Journal. 2016; 353:i2462 [DOI:10.1136/bmj.i2462] [PMID]

[2] Varmaghani M, Farzadfar F, Sharifi F, Rashidian A, Moin M, Moradi-Lakeh M, et al. Prevalence of asthma, COPD, and chronic bronchitis in Iran: A systematic review and metaanalysis. Iranian Journal of Allergy Asthma and Immunology. 2016; 15(2):93-104. https:/ /ijaai.tums.ac.ir/index.php/ ijaai/article/view/636

[3] Muneswarao J, Hassali MA, Ibrahim B, Saini B, Ali IA, Verma AK. It is time to change the way we manage mild asthma: An update in GINA 2019. Respiratory Research. 2019; 20(1):183. [DOI:10.1186/s12931-019-1159-y] [PMID] [PMCID]

[4] Pandya S. Yoga education program for reducing drug dependency and promoting better asthma control for chronic asthmatic children: A multicity experiment Global Pediatric Health. 2019; 6:2333794X19837455. [DOI:10.1177/2333794X19837455] [PMID] [PMCID]

[5] Raghavendra P, Shetty P, Shetty S, Manjunath NK, Soaji AA Effect of high-frequency yoga breathing on pulmonary functions in patients with Asthma: A randomized clinical trial Annals of Allergy, Asthma \& Immunology. 2016; 117(5):550 1. [DOI:10.1016/j.anai.2016.08.009] [PMID]

[6] Brown RP, Gerbarg PL. Sudarshan Kriya yogic breathing in the treatment of stress, anxiety, and depression: Part Ineurophysiologic model. The Journal of Alternative \& Complementary Medicine. 2005; 11(1):189-201. [DOI:10.1089/ acm.2005.11.189] [PMID]

[7] Tikle YA. General health benefits of pranayama WSR to effects on respiratory system: An ayurveda review. Journal of Drug Delivery and Therapeutics. 2020; 10(1-s):215-7. [DOI:10.22270/jddt.v10i1-s.3894]

[8] Vishvender S, Archana S, Shailaja U, Prasanna NR, Amit V. Preventive and curative aspect of yoga in management of asthma in children. Journal Homeopathy and Ayurvedic Medicine. 2014; 3(3):1-3. [DOI: 10.4172/2167-1206.1000152]
[9] Shirur SY, Pradhyumn VHC. Effect of yoga (Pranayama and Suryanamaskar) on cardio pulmonary functions among adults. International Journal of Physiology. 2019; 7(4):233-7. https://ijop.net/index.php/ijop/article/view/98

[10] Belli JFC, Chaves TC, De Oliveira AS, Grossi DB. Analysis of body posture in children with mild to moderate asthma. European Journal of Pediatrics. 2009; 168(10):1207-16. [DOI:10.1007/s00431-008-0911-y] [PMID]

[11] Agnihotri S, Kant S, Kumar S, Mishra RK, Mishra SK. The assessment of effects of yoga on pulmonary functions in asthmatic patients: A randomized controlled study. Journal of Medical Society. 2016; 30(2):98-102. [DOI:10.4103/0972-4958.182909]

[12] Turan GB, Tan M. The effect of yoga on respiratory functions, symptom control and life quality of asthma patients: A randomized controlled study. Complementary Therapies in Clinical Practice. 2020; 38:101070. [DOI:10.1016/j. ctcp.2019.101070] [PMID]

[13] Brzek A, Plinta R. Exemplification of movement patterns and their influence on body posture in younger school-age children on the basis of an authorial program "I Take Care of My Spine". Medicine (Baltimore). 2016; 95(12):e2855. [DOI:10.1097/MD.0000000000002855] [PMID] [PMCID]

[14] Soni R, Munish K, Singh KP, Singh S. Study of the effect of yoga training on diffusion capacity in chronic obstructive pulmonary disease patients: A controlled trial. International Journal of Yoga. 2012; 5(2):123-7. [DOI:10.4103/09736131.98230] [PMID] [PMCID]

[15] Mekonnen D, Mossie A. Clinical effects of yoga on asthmatic patients: A preliminary clinical trial. Ethiopian Journal of Health Sciences. 2010; 20(2):107-12. [DOI:10.4314/ejhs. v20i2.69436] [PMID] [PMCID]

[16] Sodhi C, Singh S, Dandona PK. A study of the effect of yoga training on pulmonary functions in patients with bronchial asthma. Indian Journal of Physiology and Pharmacology. 2009; 53(2):169-74. https://ijpp.com/IJPP\%20 archives/2009_53_2/169-174.pdf

[17] Gaude GS, Savadatti R, Hattiholi J. Postural correction for kyphosis improves the dyspnea index and pulmonary functions in patients with chronic obstructive pulmonary disease: A randomized trial over 12 weeks. International Journal of Health \& Allied Sciences. 2014; 3(1):44-51. [DOI:10.4103/2278-344X.130615]

[18] Greendale GA, Mcdivit A, Carpenter A, Seeger L, Huang MH. Yoga for women with hyperkyphosis: Results of a pilot study. American Journal of Public Health. 2002; 92(10):16114. [DOI:10.2105/AJPH.92.10.1611] [PMID] [PMCID]

[19] Seidi F, Rajabi R, Ebrahimi TS, Tavanai AR, Moussavi SJ. The Iranian flexible ruler reliability and validity in lumbar lordosis measurements. World Journal of Sport Sciences. 2009; 2(2):95-9. The Iranian Flexible Ruler Reliability and Validity in Lumbar Lordo (researchgate.net)

[20] Ishikawa Y, Miyakoshi N, Kasukawa Y, Hongo M, Shimada Y. Spinal curvature and postural balance in patients with osteoporosis. Osteoporosis International. 2009; 20(12):204953. [DOI:10.1007/s00198-009-0919-9] [PMID]

[21] Miller MR, Hankinson JA, Brusasco V, Burgos F, Casabur $\mathrm{R}$, Coates A, et al. Standardisation of spirometry. European Respiratory Journal 2005; 26(2):319-38. [DOI:10.1183/090319 36.05.00034805] [PMID] 
[22] Ranjita R, Hankey A, Nagendra HR, Mohanty S. Yogabased pulmonary rehabilitation for the management of dyspnea in coal miners with chronic obstructive pulmonary disease: A randomized controlled trial. Journal of Ayurveda and Integrative Medicine. 2016; 7(3):158-66. [DOI:10.1016/j. jaim.2015.12.001] [PMID] [PMCID]

[23] Chanavirut R, Khaidjapho K, Jaree P, Pongnaratorn P. Yoga exercise increases chest wall expansion and lung volumes in young healthy thais. Thai Journal of Physiological Sciences. 2006; 19(1):1-7. Microsoft Word - Chanavirut2006.doc (psu.edu)

[24] Muktibodhananda S. Hatha Yoga Pradipika. India: Yoga Publications Trust; 1993. https://www.google.com/books/ edition/Hatha_Yoga_Pradipika/Cy4DAAAACAAJ?hl=en

[25] Lunardi AC, da Silva CCBM, Rodrigues Mendes FA, Marques AP, Stelmach R, Fernandes Carvalho CR. Musculoskeletal dysfunction and pain in adults with asthma. Journal of Asthma. 2011; 48(1):105-10. [DOI:10.3109/02770903.20 10.520229] [PMID]

[26] Penha PJ, Baldini M, João SMA. Spinal postural alignment variance according to sex and age in 7-and 8-year-old children. Journal of Manipulative and Physiological Therapeutics. 2009; 32(2):154-9. [DOI:10.1016/j.jmpt.2008.12.009] [PMID]

[27] Gonçalves MA, Francisco DS, Medeiros CS, Brüggemann AK, Mazo GZ, Paulin E. Postural alignment of patients with chronic obstructive pulmonary disease. Fisioterapia em Movimento. 2017; 30(3):549-58. [DOI:10.1590/19805918.030.003.ao13]

[28] Almeida VP, Guimaraes FS, Moco VJP, Menezes SLS, Mafort TT, Lopes AJ. [Correlation between pulmonary function, posture, and body composition in patients with asthma (Portuguese)]. Revista Portuguesa de Pneumologia (English Edition). 2013; 19(5):204-10. [DOI:10.1016/j.rppnen.2013.03.005] [PMID]

[29] Dias C, Kirkwood R, Parreira V, Sampaio R. Orientation and position of the scapula, head and kyphosis thoracic in male patients with COPD. Canadian Journal of Respiratory Therapy. 2009; 45(2):30-4. CJRT Summer 2009, volume 45 (2)

[30] Shahrjerdi S, Golpayegani M, Mahmoudi F. [The effect of corrective exercises on balance in elderly women with hyperkyphosis (Persian)]. Feyz (Journal of Kashan University of Medical Sciences). 2015; 19(4):284-92. http:/ / feyz.kaums. ac.ir/article-1-2782-en.html

[31] Erdoğan Yüce G, Taşc1 S. Effect of pranayama breathing technique $\mathrm{n}$ asthma control, pulmonary function, and quality of life: A single-blind, randomized, controlled trial. Complementary Therapies in Clinical Practice. 2020; 38:101081. [DOI:10.1016/j.ctcp.2019.101081] [PMID]

[32] Kant S, Agnihotri S. Asthma diagnosis and treatment-1029. Yoga as an adjuvant therapy in asthma management. World Allergy Organization Journal. 2013; 6(suppl 1):P28. [DOI:10.1186/1939-4551-6-S1-P28] [PMCID]

[33] Das RR, Sankar J, Kabra SK. Role of breathing exercises and yoga/pranayama in childhood asthma: A systematic review. Current Pediatric Reviews. 2019; 15(3):175-83. [DO I:10.2174/1573396315666190121122452] [PMID]

[34] Robergs RA, Keteyian SJ. Fundamentals of exercise physiology: For fitness, performance, and health. $2^{\text {nd }}$ edition. Boston: McGraw-Hill; 2003. https:/ / www.worldcat.org/title/funda- mental-principles-of-exercise-physiology-for-fitness-performance-and-health/oclc/1159395967\&referer=brief_results

[35] Sedaghati P, Mohamadi B, Saki F. [The effect of trainings based on modern corrective approaches on posture status and spine function of the elderly women of Paveh City: A randomized clinical trial (Persian)]. Journal of Rafsanjan University of Medical Sciences. 2019; 18(5):469-82. http:// journal.rums.ac.ir/article-1-4430-en.html

[36] Sedaghati P, Saki F, Mohamadi B. [Investigating the effect of six weeks of functional kinesio taping on body posture and spinal function of elderly women (Persian)]. Complementary Medicine Journal. 2019; 8(4):3457-66. http://cmja. arakmu.ac.ir/article-1-605-en.html

[37] Halvorson C. Stretching to breathe: Can Yoga help your asthma? Asthma Magazine. 2002; 7(3):27-9. [DOI:10.1067/ mas.2002.124806] 
This Page Intentionally Left Blank 